\section{TOURQUAL: Proposal of a Protocol For Quality Evaluation on Services at Tourist Attractions}

\author{
Tiago Savi Mondo ${ }^{\dagger}$ \\ Instituto Federal de Santa Catarina \\ Gabriela Gonçalves Silveira Fiates $\Omega$ \\ Universidade Federal de Santa Catarina
}

\section{ABSTRACT}

Tourism has been an important economic activity worldwide in recent years, and the increasing number of tourists and the competition among destinations pressure for the highest quality possible for tourists. The objective of this research is to propose a model to analyze the quality of services at tourist attractions. The first stage consisted of two bibliometric researches being performed, in order to identify the 'state of art' and verify the existing models of quality evaluation. Identified 36 models and 211 indicators of quality. From this initial exploratory research, a preliminary theoretical model was designed which worked with 35 indicators. The second stage collected and analyzed comments left by tourists on TripAdvisor.com. Analyzed 68.301 comments about tourist attractions in eight Brazilian cities, using the software T-LAB and compared with the indicators in the preliminary theoretic model. After of 35 indicators, 23 were maintained, 12 were excluded, and three new theoretic indicators were created, which made it possible to build a model able to be empirically tested. The test was carried out with 476 tourists who evaluated tourist attractions in Florianópolis-Brazil. In the confidence and questionnaire validation test the Alpha Conbranch presented an excellent result of 0.904 confirming the proposed model.

Keywords: TOURQUAL, Service quality, Tourist attractions, Brazil.

\section{INTRODUCTION}

Tourism has been one of the fastest growing economic sectors in the world. With a GDP of approximately US\$4 trillion in 2013, there were more than 52 million international trips, according to the World Tourism Organization. In Brazil, where this research was conducted, although incipient, international tourism generates more than US\$5 billion annually. With the World Cup in 2014 and the Olympics in 2016 officials expect this number to increase dramatically. Within this context, this research proposes a model for assessing the quality of services at tourist attractions, considering the fact that tourism is a representative industry in the global economic dynamics and to date, have had no appropriate attention from the academy. Thus, a management that aims for quality of services becomes a necessity for organizations to achieve better results and continue to grow.

Sureshchandar, Rajendran and Anantharaman (2001) argue that, with the development of the service sector in almost all economies, quality is no longer the sole and exclusive concern of the physical
Corresponding author:

${ }^{\dagger}$ Instituto Federal de Santa Catarina.

E-mail: tiago.mondo@ifsc.edu.br

$\Omega^{\Omega}$ Universidade Federal de Santa Catarina.

E-mail: Gabriela.fiates@ufsc.edu.br

Received: 05/11/2015.

Revised: 08/06/2015

Accepted: 12/07/2015.

Published Online: 07/03/2017. 
goods sector. Service providers are facing the same realities in quality settings that their counterparts in production confronted in the past.

According to Teas (1994), the debate between Cronin and Taylor (1992), Teas (1993) and Parasuraman, Zeithaml and Berry (1994), resulted in the identification of several important issues concerning the conceptual and operational definitions of: a) perceived service quality; b) the role of normative expectations taken as determinants or components of perceived quality; and c) the relationship between perceived quality and customer satisfaction. Due to the importance of the concept of quality in theory and practice of areas such as marketing and production, the authors argue that these issues deserve more attention in theoretical and empirical investigations.

Some authors are pioneers in this subject such as Grönroos (1984) and later, Parasuraman, Zeithaml and Berry (1985) who proposed the measurement of service quality, based on Oliver's satisfaction model (1980). With the development of studies in the area, Parasuraman, Zeithaml and Berry (1988) reinforced their initial model by creating and disseminating the first instrument to evaluate service quality, which is well known in the academy: SERVQUAL. After this, the subject has achieved several fronts within the academy and has spread worldwide.

The dimensions of service quality in SERVQUAL were identified based on 10 items considered crucial to establish quality. Later, Parasuraman, Zeithaml and Berry (1988) reduced these items to 05 elements of satisfaction in services: confidence, responsiveness, safety, empathy and tangible aspects.

Despite the hegemony of SERVQUAL in the academy, there are debates regarding the paradox expectation/perception. Cronin and Taylor (1992) discussed this issue and criticized SERVQUAL, and created a model that uses only the perception of services as a tool for quality measurement: SERVPERF. Gronroos (2003) supports the idea by arguing that service quality should reflect, above all, what customers perceive.

SERVQUAL has been heavily criticized, either because of the assumption that the measurement of the perceived quality by itself would be enough to explain the performance of the service provider and customer satisfaction (which makes it unnecessary to measure the expected performance (Cronin \& Taylor, 1992); or because of the understanding that the attributes measured by the scale are vectorial, i.e. the consumer expectation of the attribute in its fullness is the highest standard expected (Teas, 1994).

Nevertheless, SERVQUAL is still considered the most traditional tool for measuring the perceived service quality (Hughey, Chawla \& Khan, 2003), having already been replicated many times in the national and international market. Other criticisms have been made of SERVQUAL because of the tool's focus on psychometric and methodological soundness of scales, because it is being used and tested only in developed countries, and due to the fact that the tool offers static standard measurements and disregard the service history, as well as not being able to capture the dynamics of the expectation of change (Jayasundra, et al, 2009).

The different models of quality assessment present a diversity of attributes of service quality, which can help organization's managers in determining the best strategy for customer satisfaction. However, each service can have different quality attributes, according to the specificity of each sector. Thus, searching for an appropriate assessment model seems to be relevant for a more accurate assessment.

There is one issue concerning tourism which is little addressed: how the characteristics of offered services reflect in the perception and experience of the tourist. From well known themes, understanding how this process works produces margins for new analyzes.

In the hotel business, the best worldwide known model is HOTELQUAL, an adaptation of SERVQUAL performed by Sierra et al (1999), although SERVQUAL is still the most used in the area. 
BBR

14,4

In restaurants, DINESERV is one of the most common models found in the literature. Conceived by Knutson et al (1995) it is also an adapted model of the generic SERVQUAL. However, it is rarely used in research, as observed in the exploratory research performed on the data from Ebsco which will be presented later.

There are also specific models for measuring service quality in Airline companies. Danaher (1997) developed a method for checking the quality of domestic flights, however, it is actually the SERVQUAL method with some variations, proposed by Gloudin and Kloppenborg (1991) which is most used in the industry. Other generic models are seen in the literature, such as the evaluation of service quality in historical attractions, museums and castles, called HISTOQUAL, produced by Frochot and Hughes (2001), which also derived from SERVQUAL.

It is observed, therefore, that there are some debates when it comes to measuring service quality and the models/methods/tools used to do so. This means that this is a topic that deserves more attention from scientific studies.

Grapentine (1999) corroborates saying that the initiative of creating conceptual models of quality measurement is important. Wang (2009) recently pointed out that there are still gaps to be filled and proposes future work to identify new specifics for different types of services.

In order to research the actual status of the publications about the theme, a research was conducted of the SCOPUS database for articles containing the terms 'service quality', 'model', and 'tourism', in the title, abstract or key words, resulted in a total of 66 articles. Of these, seven addressed topics related to e-commerce in tourism, not being adherent to the theme of research.

14 of the articles were not specifically related to the quality of tourism (quality in malls, health, medical tourism, education, sports, events, business and economy).

10 articles were related to service quality in hotels, using models such as IPA and Kano, in addition to articles without a specific model.

Four articles were related to service quality in travel agents (two without specific models, one using SERVQUAL and one creating a specific model for excursions).

One article dealt with tourist purchasing behavior, one with the development of tourism in China, one about cruises' brand and image. Nine articles worked the relationships between quality, experience, loyalty, satisfaction, image and/or value. With little adherence to the aim of the study. CRM was used for two articles and quality in airlines by one.

Articles about tourism in general were also analyzed. As cultural aspects of quality (1), application of SERVQUAL and/or Kano model (5), quality of touristic information (1), investigation into technical quality in tourism without a specific model (1), competitiveness of destinations (2), nature/guided tourism (2), creation of an adapted model in SERVQUAL for amusement parks.

Out of 66 articles found, 04 had adherence with the object of study and they were carefully reviewed.

Research by Moutinho, Albayrak and Caber (2012) investigated to what point the global quality of service had effects on the tourist behavior after purchase. The authors proposed a measuring scale with categories related to touristic destination such as commercial, health and hygiene, information and facilities, transport, accommodation and satisfaction, perceived value and touristic behavior. It is understood as a very different model to the one presented in this article. Firstly because it has a focus on analysis of the touristic destination and, consequentially, has distinct categories of those presented in the evaluated article.

Research by Yuan and Fu (2014) evaluated the service quality of tourism in Zhangjiaje using Grey's multilevel method. As previously mentioned, this research focused on the touristic destination rather than a specific model to analyze quality of tourist attractions as proposed in this article. The authors created primary levels of evaluation (conditions 
of infra structure of the destination, accessibility, air quality, sanitation, touristic route, service attitude, mode of service, staff image, service skill, service efficiency, diversity of visiting options, diversity of restaurants, diversity of accommodation, diversity of touristic commodities and diversity of leisure activities). It is understood that this research and the model created within do not exclude the proposal made here, as the object of analysis is different.

Chen, Lee, Chen and Huang (2010) researched behavior in relation to service quality and consumer satisfaction in a national park in Taiwan. The model created in the study is specific to national parks and the final object is not the evaluation of service quality but the relation of this with satisfaction. The model takes into account the personal interaction, the physical environment, the technical quality and the quality of accessibility. Looking closely at the model it is possible to see that it is focused exclusively on national parks making it unable to amplify to other tourist attractions.

Ryglova and Vajcnerova (2014) researched complex approaches to analyze service quality at tourist destinations. Again, it is understood that the research at destinations is different to research at attractions one being broader then other more specific. The authors use an adaptation of the ECSI model and consider one of the model dimensions for analysis of tourist attractions, without however, using elements that are more specific.

Of the four articles considered adherent to the study objectives, it is understood that the models that created them were made specifically for analysis of touristic destinations. It is understood that some indicators were converging, however the specificity to analyze the attraction itself, produces possibilities for more focused management and improvement.

When travelling, tourists relate to different actors in the sector. They use restaurants, lodging facilities, airlines, transportation companies and tourist attractions. This research focuses on just one of the dimensions: tourist attractions. In essence, tourist attractions consist of all elements of "no place" that attract tourists. They usually include landscapes to observe, and activities and experiences to take part in. The vision is one of the most important tourist attractions from a marketing point of view, having a great impact on the cognitive experience of an attraction (Lew, 1987). Leiper (1990) corroborates the issue by mentioning that tourist attractions are a system composed of three elements: a tourist or human element, a nucleus or central element, and a marker or informative element.

The basic distinction between tourist attraction and touristic destination is the amplitude of the concept. The tourist attraction is composed by the tourist, by a central element (that motivates the visit) and an informative element. The touristic destination is a collection of tourist attractions and food, transportation and accommodation facilities.

To research the quality perception about a destination is different from researching an attraction. Firstly because for the attractions, more specific indicators are used, while for destinations the indicators are more general (such as traffic, accommodation facilities and complementary services). Moreover, for tourist attractions the management of indicators is more direct than it is for destinations, which is more complex.

From all of the above, this research seeks to answer the following question: How is it possible to evaluate the quality of services at tourist attractions?

From the formulation of the problem and the research question, the general goal is: To propose a model for assessing the quality of services at tourist attractions.

\section{METHODOLOGY}

This is a constructivist, deductive and both qualitative and quantitative research in accordance with Creswell (2007). The research was divided into four stages. The first aimed to raise the existing literature on models of service quality and create a preliminary theoretical model to evaluate the quality of tourist attractions with existing models in other 
BBR

14,4

452

indicators. The second aimed to collect comments from tourists on tripadvisor.com about tourist attractions and analyze them. In the third stage the comments of tourists surveyed in the second stage were confronted with the indicators of the first stage, maintaining, deleting or creating new ones as necessary, thus articulating the final model to be tested. In the last stage of the research, the created model was tested and validated in field research.

The first methodological step of this research is the exploratory research of the bibliography and documentation. For the research strategy a bibliometric research was conducted - a practice that emerged around 1960 in the academy, recommended by Pritchard (1969).

As for the research in Brazilian publications, data was collected from the websites of Brazilian publications in the area of Administration and Tourism. The procedure was to search using key words: quality + service. This initial search resulted in 194 articles. After reviewing the titles and abstracts, 43 articles were considered adherent to the subject of this research and were then fully read.

As for the research of international publications, data was collected from Ebsco data base. At first, the strategy was to conduct the search using the words "quality" + "service" + "model". The search resulted in 368 articles that addressed several issues with these keywords. The same procedure of article selection carried out for the national publications was performed, focusing on models of service quality with managerial purposes, resulting in the full reading of 149 articles.

Models of service quality observed in the collected articles provided the basis for creating a database using the indicators used by these models. After analysis, the database allowed the creation of a preliminary theoretical model.

The preliminary model sought to encompass all the possible indicators found in the other surveyed models. First, the models were classified according to scope, dimensions, indicators, scales of measurement and presentation, in order to obtain a general overview; this process of classification was conducted using a descriptive spreadsheet. After this, all 211 indicators present in these models were identified and tabulated.

A spreadsheet list was prepared, which classified the indicators in alphabetical order. Many of the indicators were repeated (eg, trust, care, infrastructure, etc.) and many others did not adher to the scope of the tourist attractions (such as quality and quantity of collections for libraries, network structure for ICT and quality services materials for dental services). The analysis was qualitative.

All indicators were analyzed individually and screening was conducted to exclude those repeated or that did not fit the scope of the research. A final analysis was performed seeking indicators that measured similar elements. After this process, the primary model was composed of 35 indicators of quality that were used in the third stage of the research.

In the third stage, tourist comments on TripAdvisor.com were collected, based on a script, which aimed to capture all the information available on the site such as: the attraction, city, the title of the comment and the content of the comment itself. This collection was made by means of specific software created to extract data from the website.

The software was produced in ruby programming language. The destination and attractions to be researched were registered and the software organized the information on a spreadsheet with comments and comments titles. A computing engineer helped to mine the data from the website during this phase of the research.

Following the third stage, tourist attractions in eight Brazilian cities were chosen, taking into consideration the different market segmentations of tourist attractions such as beaches and nature (Florianópolis, Rio de Janeiro, Bonito, Foz do Iguaçu and Salvador), urban tourism (Curitiba), and cultural and historical tourism (Belém and Ouro Preto). The attractions were classified as suggested by Swarbrooke (2002) in natural, built with touristic purpose, built without touristic purpose and special events as well as in another 27 
sub-classifications to facilitate the process of generating the graphs of the analysis in the T-LAB software.

The sample was comprised of 57,409 comments in Portuguese and 10,892 in English. The data was tabulated and analyzed using descriptive statistics and applied using the SPSS 17 software and through content analysis by T-LAB software (sequence of words, correlation between words and cluster analysis). To analyze the comments, the Sammon method was used to analyze word correspondence and word clusters, using the T-LAB software.

With the results, the content analysis was performed to identify the terms that were adherent to the definition of quality (Navarro \& Martinez, 1995). After defining the preliminary model, from the collection and analysis of data stage 1 was compared to stage 2. The comments were compared to indicators.

Indicators that were related to the comments remained in the model, those that did not were excluded and the results of the comments that were not associated with any of the indicators provided the basis for the construction of new indicators.

Thus, this phase is characterized as qualitative, based on analysis and correlation of content. The strategy can be characterized by the use of the method of Grounded Theory, as the data allowed the construction of new indicators. Strauss and Corbin (1994) mention that the methodology of Grounded Theory can be considered as the one that emerges from the data, which are those prior to the theory.

The last step of this research, had the aim of validating the specific model created in stage 3. Therefore, other field research was conducted, in this case at tourist attractions of a relevant city. The choice of Florianópolis as the destination of the empirical test model was due to the city being present in major rankings of the best touristic destinations in Brazil in the last 10 years.

Data collection was performed by applying a structured questionnaire and not at the same time as tourists were visiting/using services at tourist attractions. The questionnaire was formally prepared and presented pre-determined questions in order. It was applied through a personal interview with tourists, performed by trained personnel as well as being applied on an online platform. A filter question was used so that the questionnaire could only be answered by tourists. The next question verified where they were from and the reason for travel (business or pleasure). If the respondent was local, they were automatically excluded from the research.

The five point Lickert scale was used to attribute value and to evaluate the indicators. According to the most common models of theoretical search, it was observed that the five point Lickert scale is the most used for research on service quality.

The sample for the study counted on 476 tourists. Data collection was performed in Florianópolis, Santa Catarina, Brazil, according to the attractions classification previously presented during February and March 2014, exclusively approaching tourists on the streets of the city center and in the bus station. Questionnaires (annex) were applied in person (206) and online (270). This choice was due to the time constraints for data collection and it was understood that only tourists who had visited the city could take the survey. However, this question is considered as a limitation of this study. The online survey link was available on social networks, tour groups and travel and e-mail groups related to tourism. This was a convenience sampling.

The researched tourists should choose a specific attraction in the city to evaluate. After the choice, they were asked about the importance of the 26 indicators for the quality of services at tourist attractions and about the actual evaluation that the tourists made on that indicator for the attraction they chose. Data was tabulated and analyzed using SPSS 17 statistical software. 


\section{RESULTS AND DISCUSSION}

For the construction of the preliminary theoretical model, according to what has been presented in methodological procedures above, models of service quality, indicators, scope, size, scales of measurement and forms of presentation were identified.

The models found in leading publications and analyzed by this research were: Method of Network Analysis (Saaty, 1996), DEA Model, IT Based Model (Zhu et al, 2002.), Jaysundara, Ngubule and Mjanja Model (2009), Haywood-Farmer Model (1988), Sweeney et. al. Model (1997), Bolton and Drew model (1991), PCP Philip and Hazlett Model (1997), HRD Model, Oh Model (1999), INTSERVQUAL of Frost and Kumar, Mackoy and Spreng Model (1996), HSE Model, Lijander and Strandvik Model, Gummeson Model, Ideal Value Model of Mattson (1992), Brogowicz et. al. Model (1990), Dabholkar Model (1996), Berkey and Gupta Model (1994), TAM Model, IPA Model, CAF Model, Candido and Morris Model (2010), ACSI Model, Oliver Model (1993), Just in Time Model, TQM, Kano Model (1984), Brady and Cronin Model (2001), Groonros Model, SERVQUAL and SERVPERF.

Of the 32 models analyzed, 22 are considered general, designed to evaluate the services broadly, while the other 10 are considered to be specific, where they try to meet the demand for measurement of service quality in certain activities of the sector. It is noted that a model for measuring service quality at tourist attractions was not found, except for HISTOQUAL, which is specific to historical attractions.

There was also the occurrence and existence of measurement indicator of each model. Of the 32 models, 19 had no indicators, the other 13 possessed an average of 21 indicators per model.

The measurement scales were also investigated. They were found exclusively using the Likert scale as a way of measuring the indicators in 15 models, 10 with a seven-point scale, one with a six-point scale and four with a five-point scale.

When analyzing the models content, it was observed that, in general, they are based on the assumption that they had to analyze any type of service, with no specifics, and they took into consideration basically human features and characteristics of infra-structure of the services operation.

In the specific models, it was verified that they were deeper regarding the context using indicators and measurement scales focused on the indicators aims. The difference between the models considered as general (especially SERVQUAL, SERVPERF, KANO, GRONROOS and Brady and Cronin) is that they did not serve to specific measurement demands for quality (and it is at this point that the specific models can be used to fill these theoretical and practical gaps). As mentioned before, it is important to stress the relevance of the model proposed in this work, since specific models to measure the quality of tourist attractions have not been found in literature (bibliometric research on EBSCO and SCOPUS databases). Even finding some models for touristic destinations, it is understood that they present the same rationale used from general to specific models. The models that aim to measure the quality of the destination do not serve to the demands and the indicators appropriate to evaluate the attractions.

Of the researched models, 211 indicators with different characteristics were identified. After selection and analysis, 35 indicators remained, which were the basis for the analysis of tourists comments on tripadvisor.com. As $75 \%$ of the models found in the literature had dimensions of analysis, it was decided that categories and indicators would be created, following a qualitative analysis of the models already presented. Thus, the six categories were defined: access, human element, environment, safety, experience and technical quality (Table 1). 
Table 1. Indicators of the preliminary theoretic model

\begin{tabular}{|c|c|c|c|c|c|}
\hline Category & & Indicator & Category & & Indicator \\
\hline Access & 1 & Accessibility/Location/Parking & Experience & 20 & Learning from the attraction \\
\hline Access & 2 & Accessibility (People with disabilities) & Experience & 21 & Attraction's entertainment \\
\hline Access & 3 & Accessible toilets & Experience & 22 & Aesthetic - Attraction's beauty \\
\hline Access & 4 & Queues - Waiting for service & Experience & 23 & $\begin{array}{c}\text { Escape - Attraction offers breaking } \\
\text { the routine }\end{array}$ \\
\hline Access & 5 & Ease of Purchase & Safety & 24 & Fire system warning \\
\hline Access & 6 & Opening hours & Safety & 25 & Safety \\
\hline Access & 7 & Outdoor signage & Safety & 26 & $\begin{array}{l}\text { Client safety and protection in the } \\
\text { transactions }\end{array}$ \\
\hline Environment & 8 & Temperature & Technical quality & 27 & Good service, cost and price \\
\hline Environment & 9 & Comfortable and inviting place & Technical quality & 28 & Service capacity \\
\hline Environment & 10 & Silence & Technical quality & 29 & External communication \\
\hline Human element & 11 & Anticipation - Pro-activity of the attendant & Technical quality & 30 & Weather conditions \\
\hline Human element & 12 & Clean and professional image of employees & Technical quality & 31 & Innovation in the service \\
\hline Human element & 13 & Presentation of the service to clients & Technical quality & 32 & $\begin{array}{l}\text { Equipment and environment } \\
\text { maintenance }\end{array}$ \\
\hline Human element & 14 & Attention of the employee to the client & Technical quality & 33 & Prompt response to solicitations \\
\hline Human element & 15 & Service in case of complaint & Technical quality & 34 & Indoor signage \\
\hline Human element & 16 & Problem solving capability & Technical quality & 35 & Technology \\
\hline Human element & 17 & Trust of the tourist towards the attendant & & & \\
\hline Human element & 18 & Knowledge of the attendant & & & \\
\hline Human element & 19 & Cultural sensitivity during the service & & & \\
\hline
\end{tabular}

Source: Prepared by the authors from primary data (2014).

The categories were defined following the logic of the operation of the service; how the tourist arrived at the attraction (access), if there was a pre-purchase stage, how they view the environment, employees, safety and the technical quality of the tourist attraction, including the service they received. Finally, their perception of the service related to the post-purchase phase. Figure 1 shows the model with the preliminary categories of indicators.

\subsection{ANALYSIS OF TOURISTS COMMENTS ON TRIPADVISOR. COM}

This stage aimed to collect comments from tourists to confirm, exclude or create new indicators for the preliminary model. On the site TripAdvisor.com, 57,408 comments were collected from 08 Brazilian touristic destinations (Florianópolis, Curitiba, Foz do Iguaçu, Rio de Janeiro, Ouro Preto, Bonito, Salvador and Belém) in February 2014. This provided a collection of separate comments, with diverse analysis focus so that the analysis could be more general. The software developed for data mining was programmed to collect all comments that existed at the time, about tourist attractions in the city.

Of all the comments about the destinations, Rio de Janeiro had the highest number of occurrences analyzed 20,913 (36.42\%). Curitiba and Foz Do Iguacu were next with 9,924 $(17.28 \%)$ and $9,103(15.85 \%)$, respectively. Salvador had 6,237 comments, representing $(10.86 \%)$ of the total. Florianópolis had 3,674 comments $(6.4 \%)$ added to these the 3053 comments about tourist attractions in Belém-PA (5.31\%), 2,542 about Bonito-MS (4.42\%) and 1,962 comments about Ouro Preto-MG, representing $3.41 \%$ of the total.

The comments were collected from the attractions of each city announced on the website. In Rio de Janeiro there were 204 attractions, in Belém 36, 19 in Bonito, 70 in Curitiba, 71 in Florianópolis, 30 in Foz do Iguaçu, 37 in Ouro Preto and 65 in Salvador, totaling 532 attractions researched. The average number of comments per attraction totaled 107. 
BBR

14,4

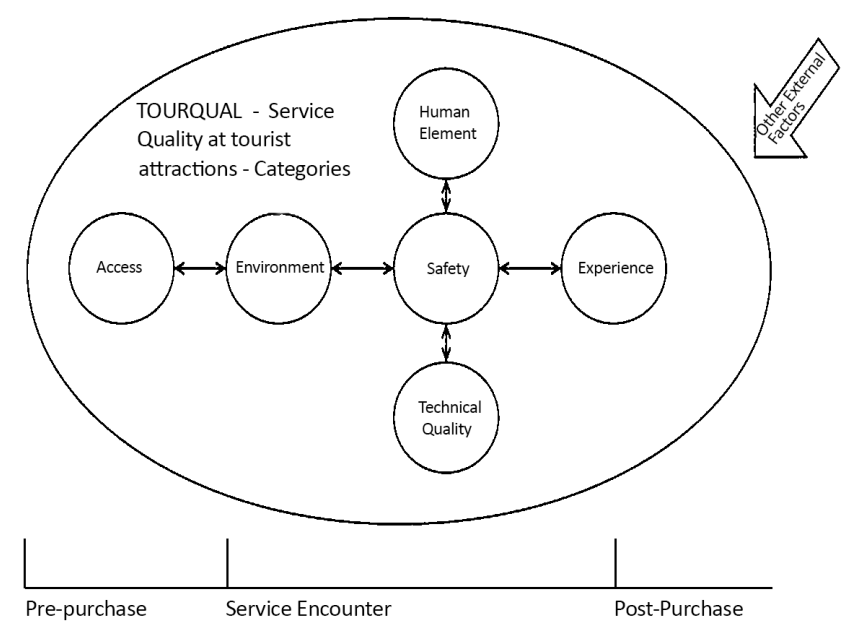

Figure 1. Diagram of preliminary model

Source: Prepared by the authors (2014).

\subsection{RELATIONSHIP BETWEEN INDICATORS AND COM- MENTS}

Tests were carried out on all the comments collected from site TripAdvisor.com using text analysis TLAB software and tests of Sammon, Analysis of Cluster and Correspondence of words. After submitting the analyzed content to the preliminary theoretical model, the indicators were confirmed, excluded and created, enabling the final model to be built and the indicators to be tested in field research.

The Sammon Mapping or Sammon projection is an algorithm that maps a larger dimensional space to a space of smaller dimension, seeking to preserve the distances between the points of the larger dimension in its smaller projection of smaller dimension. This method is particularly useful for exploratory data analysis, and was proposed by John W. Sammon in 1969.

The correspondence analysis highlights the similarities and differences between the units of the context. Specifically in the T-LAB, the test can be applied in texts, with words to identify variables (which is the case in this thesis), groups of basic contexts of words as co-occurrences of values and tables to verify the occurrence of values. The results of the analysis allow graphics to be drawn, which show the relationship between the subgroups (body of the text and lexical units that form the subgroups). More precisely, according to this case, the type of graphics show the relationship between the active variables and "lemmas".

The algorithm for the calculation and the exits are similar to the units of lexical analysis by variable tables. The cluster analysis was made using the Ward method, i.e, establishing hierarchy of variables presence.

This software and the tests used, resulted in figures with the main terms in the tourists comments. These terms were the result of tests based on mathematical algorithms. It was decided that these figures would be analyzed in a qualitative way. The key terms were individually analyzed for adherence to the preliminary model indicators. The terms that adhered were selected and those that did not were deleted. A spreadsheet was used to control the inserts. After this process, 23 indicators from the preliminary theoretical model were maintained/confirmed. 
From the tourist comments, 12 indicators were not adherent: outdoor signage, anticipation, silence, clean and professional image of employees, problem solving capability, cultural sensitivity during the service, fire warning system, safety in transactions, innovation in service and prompt response to solicitations.

Other indicators were adapted according to the tourists' comments. In the temperature indicator, the issue of acoustics and silence was included. The quality of service in case of complaints was considered as part of the indicator about the quality of service in general. In the indicator about safety, issues such as hawkers, beggars and police force were included. In the service indicator, the issues of attractive infrastructure and equipment were included, plus complementary attractive infrastructure such as restaurants, auxiliary equipment and other objects that may be offered.

In addition to the exclusions and adjustments, three indicators that were not in the preliminary model were included: cleaning, capacity (volume of people that can be served simultaneously) and variety of activities. The resulting model, called TOURQUAL Model can be seen in Table 2.

The TOURQUAL Model was formed from the existing theoretical models in the literature, coming from the bibliometric research and correlated with tourist comments, using analysis provided by the T-LAB software and qualitative analysis. The categories of the final model are discussed below.

\subsection{ACCESS CATEGORY}

The access category is the first set of indicators in which the tourist will have contact with the service. It consists of the following indicators:

Accessibility/Location: concerns the access to the attraction such as highways to arrive, sidewalks or stairs to climb, moreover, the ease of access to the attraction, including issues of difficulty in finding the location, parking and ease of entry and exit.

Accessibility for people with disabilities: Around the world there are laws to make attractions accessible for tourists with disabilities. Adapting attractions so that all tourists have the same opportunities is an indicator of quality in this research.

Access to bathrooms: According to Greed (2004), bathrooms are a vital component in creating accessible, sustainable and comfortable cities for all. This indicator also includes the issues related to hygiene, environment and structural layout of these facilities.

Waiting for service: Voorhees et. al. (2009) argue that when consumers have to wait, the process of provision of services is often compromised.

Ease of purchase: This indicator refers to the process the customer has to go through in order to make a purchase, before entering the attraction. Items such as availability of contacts (e-mail, phone, website), selling points at touristic facilities, are elements of operation of this indicator.

Opening hours: The hours of operation are considered an indicator of the access category as they limit the possibility of access to the attraction. Often the attractions are not open at peak times which can result in bad service evaluation.

\subsection{ENVIRONMENT CATEGORY}

The environment category takes into account the atmosphere of the service that tourists find at the attraction. According to Bitner (1992), the effect of the environment or the physical design and décor elements are acknowledged by consumers, workers and by marketing managers, retail, services and specialized magazines. The indicators of the environment category used in the models are: 
BBR

14,4

458
Table 2. TOURQUAL Model

\begin{tabular}{lc}
\hline Category & Indicator \\
\hline Access & Accessibility/Location \\
Access & Accessibility (People with disabilities) \\
Access & Accessible toilets \\
Access & Waiting for service \\
Access & Ease of Purchase \\
Access & Opening hours \\
Environment & Temperature/Acoustic \\
Environment & Comfortable and inviting place \\
Human element & Presentation of the service to clients \\
Human element & Attention of the employee to the client \\
Human element & Service in general \\
Human element & Trust of the tourist towards the attendant \\
Human element & Knowledge of the attendant \\
Experience & Learning from the attraction \\
Experience & Attraction's entertainment \\
Experience & Aesthetic - Attraction's beauty \\
Experience & Escape - Attraction offers breaking the routine \\
Safety & Safety \\
Technical quality & Price \\
Technical quality & Weather conditions \\
Technical quality & Maintenance (equipments and infrastructure) \\
Technical quality & Signage \\
Technical quality & Technology \\
Technical quality & Cleaning \\
Technical quality & Load capacity \\
Technical quality & Variety of activities \\
\hline Source: Prepared by the authors from primary data (2014) &
\end{tabular}

Temperature/Acoustics: Bitner (1992) mentions that the customer can shiver or perspire and that management of the temperature is an indicator of the overall quality of the attraction.

Comfortable and inviting place: A well equipped theater and other environment indicators make tourists feel good. This indicator concerns the comfort and pleasure to be in a place.

\subsection{HUMAN ELEMENT CATEGORY}

When developing SERVQUAL, Parasuraman et al. (1988) focused primarily on the human aspects of service provision, considering that trust, responsiveness and empathy are mostly human dimensions. Bitner et al (1990) found that in service encounters, the behavior of the service provider impacts on the perceptions of service quality for customers. Therefore, companies have to train their staff in interpersonal skills in order to present a true customer focus. Mills and Morris (1986), Schneider and Bowen (1992) and Stebbing (1993) also emphasized the role of human aspects in service delivery.

Presentation of service: Refers to how the employee represents the attraction. The tone of voice, presentation content, speed and other variables can influence the perception of quality in the presentation of the service.

Attention: This indicator refers to levels of attention the employee gives to the tourist at the attraction. The employee's attention in providing the service in the best possible way together with attention to meet the specific needs of each client. 
Normal service and complaints: Often the service is not rendered properly. However, there is a possibility of recovery of the service quality and future customer satisfaction (Santos, Costa \& Mondo, 2011).

Trust: Morgan and Hunt (1994) define trust as the perception of the reliability and integrity of a partner. Garbarino and Johnson (1999) suggest that when a customer trusts an organization, he is sure of the quality of services offered. All these definitions highlight the importance of this item in the quality of services.

Technical knowledge of the employee: The historical, geographical, or economic aspects and all other information concerning the attraction must be well known by the front line staff.

\subsection{EXPERIENCE CATEGORY}

The tourist's experience at the attraction has to be taken into account when measuring the quality of services of an attraction. Pine and Gilmore (1999), when defining experience economy, produced four dimensions of experience for the consumer/tourist.

Learning: This indicator relates to how much a tourist learns at an attraction. Many tourists do not seek to learn when travelling, however, they end up learning when participating in a tour or from reading information boards.

Entertainment: Entertainment, according to Pine and Gilmore (1998), has passive participation and direct connection to the environment and refers to the reaction of individuals in relation to the elements that are available to them, using the five senses, providing satisfaction, laughter or relaxation.

Evasion: This involves the active participation related to immersion in the environment. In this dimension, those proposing the activity have the responsibility of keeping the consumer immersed, maintaining their attention (Pine \& Gilmore, 1998).

Aesthetic: According to Tuan (1980, p 74), "evaluation of the environment by the visitor is primarily aesthetic. It is the perspective of a stranger. The stranger judges by appearance, for some formal criterion of beauty". And this is an aspect that can be observed at touristic attractions, as the vision for the visitor is of the moment, they are there in passing, it is the attraction's image, it's aesthetic.

\subsection{SAFETY CATEGORY}

This category has a single indicator. Safety, according to Berkley and Grupta (1994) is the freedom from danger, risk or doubt. It includes physical, mental and financial safety. At tourist attractions, safety is considered important because it shows the care and attention tourists receive. Safety makes the tourist feel free from danger to enjoy the attraction.

\subsection{TECHNICAL QUALITY CATEGORY}

Following the above by Gronroos (1984), the technical quality is the quality of what the consumer actually receives as a result of their interaction with the service company. It is important for the tourist and his evaluation of the attraction.

Good service, reasonable cost, with guarantee of quality (price): The question of the amount charged is also regarded as influential in the degree of quality perceived by the customer/tourist. Thus, good service should theoretically have a reasonable cost for the client, without jeopardizing the quality. Identifying customer perception with the cost / benefit ratio is also a measure of the quality of the proposed model.

Weather conditions: It seems obvious to consider that with outdoor attractions the indicator of weather conditions is more influential than the quality of indoor attractions. Thus, even though the attraction and the destination do not have control over the weather, 
BBR

14,4

it is considered a relevant indicator for some types of attraction and therefore is present in the model.

Maintenance and Infrastructure: This indicator refers to the maintenance of equipment, materials and tools available at the attraction. The service quality is measured here from the availability of maintenance services at the attraction and of how they are at the time of consumption.

Indoor signage: Enters the model for the possibility of orientation within the tourist attraction. This indicator becomes even more important for service quality when there are no guides at the attraction, i.e. when it is self service.

Technology at the attraction: Technology at the attraction is an indicator designed to measure how technologically developed the attraction is. At a time when virtually everything has become digital, offering the customer modern-edge technologies is considered an indicator of performance in the measurement of service quality.

In addition to the indicators, the TOURQUAL model also features an assessment protocol, using a questionnaire to be applied to the tourist.

The questionnaire was created from the knowledge and study of the models presented in stage 1 of the results of this research. The format was chosen to identify solely the perceptions of the service quality after the tourist had used them, supporting the ideas of Cronin and Taylor (1992) and Brady and Cronin (2001).

\subsection{EMPIRICAL TEST MODEL}

After the construction of the final theoretical model and the empirical instrument of data collection, this section aims to present the results of field research to validate the model, carried out in Florianopolis, Santa Catarina, Brazil, which is considered the third best destination for leisure tourism in Brazil (Mtur, 2013).

\subsubsection{RESPONDENTS PROFILE}

Data collection was carried out in person through interviews based on the questionnaire and virtually where the questionnaire was completed online. The questionnaire was sent in real time to an internet cloud, enabling the joint analysis of collection types.

The questionnaire was visited 824 times and started by 739 tourists. After the exclusion of invalid questionnaires, a sample of 476 questionnaires (206 in person and 270 online) was reached. The invalid questionnaires were those that were initiated and responded to the first or second question only. Regarding gender, the sample was homogeneous, with 51.4\% of women and $48.6 \%$ of men answering the survey. Statistics of marital status showed that $155(49.2 \%)$ of respondents were married, followed by 129 Single (41\%), 29 divorced $(9.2 \%)$ and two widowed $(0.6 \%)$. Finally, the age of the respondents was an average of 34.21 years, with the standard deviation of 10.27 years, resulting in $95 \%$ of the sample being in the range of 24 to 45 years.

Table 3 presents the evaluation of the importance of the indicators for service quality of the attraction and the evaluation of the indicator in the researched touristic attraction.

It is noticed that 22 of the 26 indicators have importance above index 4 ( $1=$ not important and $5=$ very important). This shows a qualitative validation of the protocol, since $84.6 \%$ of tourists consider them very important.

Furthermore, the evaluation found that $76.9 \%$ of the indicators had not obtained positive evaluation considering that the first level was considered very bad, level 2 bad, level 3 regular and levels 4 and 5 good and excellent, respectively. This shows that the city of Florianópolis needs improvement to increase perceived quality of attractions by tourists in the city. 
Table 3. General evaluation of the indicators

\begin{tabular}{lccc}
\hline Importance of the Indicator & Value & Indicator Quality & Value \\
\hline Technical knowledge & 4,7 & Accessibility (People with disabilities) & 2,68 \\
Cleaning & 4,68 & Bathrooms & 2,74 \\
Safety & 4,66 & Technology & 3,01 \\
Aesthetic & 4,62 & Location & 3,24 \\
Infrastructure & 4,57 & Price & 3,27 \\
Attention & 4,56 & Indoor signage & 3,3 \\
Comfort & 4,54 & Safety & 3,38 \\
Escape & 4,51 & Learning & 3,48 \\
Price & 4,5 & Infrastructure & 3,49 \\
Bathrooms & 4,44 & Cleaning & 3,54 \\
Accessibility (People with disabilities) & 4,42 & Variety of activities & 3,64 \\
Indoor signage & 4,41 & Waiting for service & 3,67 \\
Trust & 4,39 & Services & 3,71 \\
Waiting for service & 4,39 & Load capacity & 3,74 \\
Location & 4,36 & Ease of purchase & 3,79 \\
Services & 4,35 & Trust & 3,84 \\
Weather conditions & 4,35 & Presentation of the service & 3,86 \\
Opening hours & 4,34 & Temperature/Acoustic & 3,87 \\
Entertainment & 4,31 & Attention & 3,89 \\
Ease of purchase & 4,27 & Comfort & 3,96 \\
Presentation of the service & 4,24 & Opening hours & 4 \\
Variety of activities & 4,15 & Entertainment & 4 \\
Temperature/Acoustic & 3,83 & Weather conditions \\
Learning & 3,82 & Technical knowledge & 4,04 \\
Load capacity & 3,82 & Escape & 4,23 \\
Technology & 3,74 & Aesthetic & 4,37 \\
Sore: Pric & & 4,38 \\
\hline
\end{tabular}

Source: Primary data (2014)

\subsubsection{EMPIRICAL TEST MODEL}

From the identification of the non-normality of the data, the stage of empirical test model was started and Cronbach Alpha test was used for this procedure. Gliem and Gliem (2003) state that the Cronbach Alpha test is a mathematical algorithm that results in a reliability coefficient of the questionnaire using Likert type scales.

When identifying the reliability of the 52 questions related to the importance and the evaluation of the 26 indicators of the model, the Cronbach's Alpha test resulted in 0,904. In order to verify the reliability of the constructs importance/value of indicators and the evaluation of them, they were tested separately. The test with the indicators of importance resulted in 0,858 . For the evaluation of the indicators, the reliability index generated from the test was 0.895 .

This data shows a high level of reliability of the applied questionnaire. This fact shows that the final model, applied empirically in the city of Florianópolis, is validated from the statistical viewpoint. In addition, the high level of importance assigned by tourists to the indicators shows that, qualitatively, the model also has a high reliability rate. 
BBR

\section{FINAL CONSIDERATIONS}

Tourism has been an important economic activity worldwide in recent years, and the growing desire of people to travel presents unprecedented opportunities for cities that have touristic potential to develop.

Considering the growth in the number of tourists in the world, destinations have become increasingly competitive. The competition in the tourism market is observed in practice by the level of tourist services offered. Hence the importance of the issue of service quality at tourist attractions, and this research proposed a specific model for evaluating the quality of services at tourist attractions.

Although there are many models for some sectors of the service economy, none of the findings focused on tourist attractions. Thus, recognizing that trips, places and experiences that tourists take part in when travelling are part of their satisfaction; and the fact that the indicators identified from tourist comments (database for this research) were not found in the literature, proved the relevance of this research and the correct choice of the theory based on data as its methodological tool.

Some limitations were identified in the research. Despite the use of software to analyze the content of the comments, there is a possibility of some indicators having gone unnoticed due to the use of the most relevant key terms.

In the empirical part, splitting the form of sample collection (online and field) was considered a limitation of the research, however, because of temporal resources it was not possible to apply it in just one way.

This model can be considered essentially static. However, from the moment that its instrument is applied periodically to tourist attractions and their data are compiled from temporal units, it automatically becomes dynamic. Notwithstanding, it is suggested that further studies be conducted to validate the dynamics of the model which requires longitudinal research and verification of the behavior of indicators in relation to time.

The main academic contribution of the model also considers the possibility of application and comparison of different tourist attractions at different destinations. The multiplicity of motivations for travel and various aspects of tourist destinations means that many differences exist, and a model like the one proposed here makes them have equal comparative basis for subsequent management, research and inferences.

\section{MANAGERIAL AND ACADEMIC CONTRIBUTIONS}

The main practical/managerial contribution of the research is the proposal of a new and exclusive model to research tourist attractions that goes beyond the existent literature in the field (which presents studies/models only for tourist destinations). The research carried out for this article creates better indicators regarding the services provided at tourist attractions.

As suggestions for future research, it is indicated first, that the exercise of specifying models for quality evaluation continues. Whether for types of tourist attractions or other service offerings. For example, the model proposed here may be adapted to evaluate more specific attractions, such as beaches or caves. In depth study of the applications of the model will produce knowledge to better manage the specificities of these types of attractions.

It is possible to argue that the model proposed in this research presents to the literature on the field, an expansion of the general models of service quality and of the specific models regarding tourism, presenting a deeper view with new indicators focused on tourist attractions. Destination managers, attraction managers, scholars who research and search for continuous improvement in services of parks, beaches, museums, theaters, nature, stadiums, monuments and other tourist attractions will have practical material aimed at increasing the quality perceived by tourists and therefore improving the image of the attraction and of the destination. 
Furthermore, it is suggested that this model is adaptated for the application not only at destinations (which have an overview of all indicators), but for specific attractions, adapting the questionnaire according to the indicators on site. Finally, this research presents to the academy new methodological analysis procedures (using netnography, grounded theory, content analysis and statistical analysis) and a new theoretical model specific to tourist attractions.

\section{REFERENCES}

Berkley, B. J., \& Gupta, A. (1994). Improving service quality with information technology. International Journal of Information Management, 14(2), 109-121.

Bitner, M. J. (1990). Evaluating service encounters: the effects of physical surroundings and employee responses. the Journal of Marketing, 69-82.

Bitner, M. J. (1992). Servicescapes: the impact of physical surroundings on customers and employees. The Journal of Marketing, 57-71.

Bolton, R. N., \& Drew, J. H. (1991). A longitudinal analysis of the impact of service changes on customer attitudes. The Journal of Marketing, 1-9.

Brady, M. K., \& Cronin Jr, J. J. (2001). Some new thoughts on conceptualizing perceived service quality: a hierarchical approach. Journal of marketing, 65(3), 34-49.

Brogowicz, A. A., Delene, L. M., \& Lyth, D. M. (1990). A synthesised service quality model with managerial implications. International Journal of Service Industry Management, 1(1), 27-45.

Candido, C. J., \& Morris, D. S. (2000). Charting service quality gaps. Total Quality Management, 11(4-6), 463-472.

Chen, C. M., Lee, H. T., Chen, S. H., \& Huang, T. H. (2011). Tourist behavioural intentions in relation to service quality and customer satisfaction in Kinmen National Park, Taiwan. International Journal of Tourism Research, 13(5), 416-432.

Creswell, J. W., \& Clark, V. L. P. (2007). Designing and conducting mixed methods research. Thousand Oaks, CA: Sage publications.

Cronin Jr, J. J., \& Taylor, S. A. (1992). Measuring service quality: a reexamination and extension. The journal of marketing, 55-68.

Dabholkar, P. A. (1996). Consumer evaluations of new technology-based self-service options: an investigation of alternative models of service quality.International Journal of research in Marketing, 13(1), 29-51.

Danaher, P. J. (1997). Using conjoint analysis to determine the relative importance of service attributes measured in customer satisfaction surveys.Journal of Retailing, 73(2), 235-260.

Frochot, I., \& Hughes, H. (2000). HISTOQUAL: The development of a historic houses assessment scale. Tourism management, 21(2), 157-167.

Frost, F. A., \& Kumar, M. (2000). INTSERVQUAL-an internal adaptation of the GAP model in a large service organisation. Journal of Services Marketing, 14(5), 358-377.

Garbarino, E., \& Johnson, M. S. (1999). The different roles of satisfaction, trust, and commitment in customer relationships. the Journal of Marketing, 70-87.

Gliem, J. A., \& Gliem, R. R. (2003). Calculating, interpreting, and reporting Cronbach's alpha reliability coefficient for Likert-type scales. Midwest Research-to-Practice Conference in Adult, Continuing, and Community Education.

Gourdin, k. M., Gourdin, k. N., \& Kloppenborg, t. J. (1991). Identifying service gaps in commercial air travel: the first step toward quality improvement. Transportation Journal, 22-30.

Grapentine, T. (1998). The history and future of service quality assessment: connecting customer needs and expectations to business processes.Marketing Research, 5-20.

Greed, C. (2004). Public toilets: the need for compulsory provision.Proceedings of the ICE-Municipal Engineer, 157(2), 77-85.

Grönroos, C. (1984). A service quality model and its marketing implications.European Journal of marketing, $18(4), 36-44$.

Grönroos, C. (2003). Service management and marketing: managing the moments of truth in service competition. Lexington, MA: Lexington Books.

Gummesson, E. (1993). Quality management in service organizations: an interpretation of the service quality phenomenon and a synthesis of international research. ISQA.

Gupta, A. K. (2011). A conceptual JIT model of service quality. International Journal of Engineering Science and Technology, 3(3), 2214-2227. 
BBR

14,4

Haywood-Farmer, J. (1988). A conceptual model of service quality.International Journal of Operations \& Production Management, 8(6), 19-29.

Hughey, D. W., Chawla, S. K., \& Khan, Z. U. (2003). Measuring the quality of university computer labs using SERVQUAL: a longitudinal study. Quality Management Journal, 10(3).

Jayasundara, C., Ngulube, P., \& Minishi-Majanja, M. K. (2009). A theoretical model to predict customer satisfaction in relation to service quality in selected university libraries in Sri Lanka. South African Journal of Libraries and Information Science, 75(2), 179-194.

Kano, N., Seraku, N., Takahashi, F., \& Tsuji, S. (1984). Attractive quality and must-be quality. Journal of the Japanese Society for Quality Control, 14(2), 147-156.

Knutson, B. J., Stevens, P., \& Patton, M. (1996). DINESERV: Measuring service quality in quick service, casual/theme, and fine dining restaurants.Journal of Hospitality \& Leisure Marketing, 3(2), 35-44.

Leiper, N. (1990). Tourist attraction systems. Annals of tourism research,17(3), 367-384.

Lew, A. A. (1987). A framework of tourist attraction research. Annals of tourism research, 14(4), 553-575.

Liljander, V., \& Strandvik, T. (1997). Emotions in service satisfaction. International Journal of Service Industry Management, 8(2), 148-169.

Malhotra, N. K. (2006). Marketing Research: An Applied Orientation, 5/E. Pearson Education.

Mattsson, J. (1992). A service quality model based on an ideal value standard. International Journal of Service Industry Management, 3(3), 18-33.

Mills, P. K., \& Morris, J. H. (1986). Clients as "partial” employees of service organizations: Role development in client participation. Academy of Management Review, 11(4), 726-735.

Morgan, R. M., \& Hunt, S. D. (1994). The commitment-trust theory of relationship marketing. the journal of marketing, 20-38.

Moutinho, L., Albayrak, T., \& Caber, M. (2012). How Far does Overall Service Quality of a Destination Affect Customers' Post-Purchase Behaviours?. International Journal of Tourism Research, 14(4), 307322.

Mtur. (2013) Data from the ministry of tourism in Brazil.

Navarro, P. N., \& Martínez, C. D. (1995). Análisis de contenido (pp. 177-224). Síntesis.

Oh, H. (1999). Service quality, customer satisfaction, and customer value: A holistic perspective. International Journal of Hospitality Management, 18(1), 67-82.

Oliver, R. L. (1980). A cognitive model of the antecedents and consequences of satisfaction decisions. Journal of marketing research, 460-469.

Oliver, R. L. (1993). A conceptual model of service quality and service satisfaction: compatible goals, different concepts. Advances in services marketing and management, 2(4), 65-85.

Parasuraman, A., Zeithaml, V. A., \& Berry, L. L. (1985). A conceptual model of service quality and its implications for future research. the Journal of Marketing, 41-50.

Parasuraman, A., Zeithaml, V. A., \& Berry, L. L. (1988). Refinement and reassessment of the SERVQUAL scale.

Parasuraman, A., Zeithaml, V. A., \& Berry, L. L. (1988). Servqual. Journal of retailing, 64(1), 12-40.

Parasuraman, A., Zeithaml, V. A., \& Berry, L. L. (1994). Reassessment of expectations as a comparison standard in measuring service quality: implications for further research. the Journal of Marketing, 111124.

Philip, G., \& Hazlett, S. A. (1997). The measurement of service quality: a new PCP attributes model. International Journal of Quality \& Reliability Management, 14(3), 260-286.

Pine, B. J., \& Gilmore, J. H. (1999). The experience economy: work is theatre \& every business a stage. Harvard Business Press.

Pritchard, A. (1969). Statistical bibliography or bibliometrics. Journal of documentation, 25, 348.

Ryglová, K. A. T. E. Ř. I. N. A., \& Vajčnerová, I. (2014). Possible complex approaches towards evaluating the quality of a destination in the context of tourism management. Agricultural Economics (Zemědělská Ekonomika), 60(5), 199-207.

Saaty, T. L. (2008). Decision making with the analytic hierarchy process.International journal of services sciences, 1(1), 83-98.

Santos, A. R., Mondo, T. S., \& da Costa, J. I. P. (2011). Guest's perception of quality after failure occurrences: a study of service recovery on the lodging segment. Estudios y Perspectivas en Turismo, 20(1), 110-126.

Schneider, B., \& Bowen, D. E. (2010). Winning the service game (pp. 31-59). Springer US.

Sierre Diez, B. S. (1999). HOTELQUAL: Una escala para medir la calidad percibida en servicios de alojamiento. Estudios turísticos, 95-110. 
Spreng, R. A., \& Mackoy, R. D. (1996). An empirical examination of a model of perceived service quality and satisfaction. Journal of retailing, 72(2), 201-214.

Stebbing, L. (1990). Quality management in the service industry. Ellis Horwood.

Strauss, A. \& Corbin, J. (1994). Grounded theory methodology. Handbook of qualitative research, 273-285.

Sureshchandar, G. S., Rajendran, C., \& Anantharaman, R. N. (2002). The relationship between service quality and customer satisfaction-a factor specific approach. Journal of services marketing, 16(4), 363-379.

Swarbrooke, J. (2002). The development and management of visitor attractions. Routledge.

Sweeney, J. C., Soutar, G. N., \& Johnson, L. W. (1997). Retail service quality and perceived value: a comparison of two models. Journal of Retailing and Consumer Services, 4(1), 39-48.

Tam, J. L. (2004). Customer satisfaction, service quality and perceived value: an integrative model. Journal of marketing management, 20(7-8), 897-917.

Teas, R. K. (1993). Expectations, performance evaluation, and consumers' perceptions of quality. The journal of marketing, 18-34.

Teas, R. K. (1994). Expectations as a comparison standard in measuring service quality: an assessment of a reassessment. The journal of marketing, 132-139.

Tuan, Y. F. (1980). Rootedness versus sense of place. Landscape, 24(1), 3-8.

Voorhees, C. M., Baker, J., Bourdeau, B. L., Brocato, E. D., \& Cronin, J. J. (2009). It Depends Moderating the Relationships Among Perceived Waiting Time, Anger, and Regret. Journal of Service Research, 12(2), 138-155.

Wang, C. Y. (2009). Investigating antecedents of consumers' recommend intentions and the moderating effect of switching barriers. The Service Industries Journal, 29(9), 1231-1241.

Yuan, Y., \& Fu, W. (2014, June). Quality evaluation of tourism service based on multi-level grey theory-A case study of Zhangiajie city. In Service Systems and Service Management (ICSSSM), 2014 11th International Conference on (pp. 1-6). IEEE.

Zhu, F. X., Wymer, W., \& Chen, I. (2002). IT-based services and service quality in consumer banking. International Journal of Service Industry Management, 13(1), 69-90. 